OPEN ACCESS

Edited by:

Nicole Gallo-Payet, Université de Sherbrooke,

Canada

Reviewed by:

Pierre Val,

Centre national de la recherche scientifique (CNRS), France

David Breault,

Boston Children's Hospital, USA

Steven Douglas Morley, University of Edinburgh, UK

*Correspondence:

Gary Douglas Hammer ghammer@med.umich.edu

Specialty section:

This article was submitted to Neuroendocrine Science,

a section of the journal

Frontiers in Endocrinology

Received: 29 September 2016

Accepted: 03 March 2017

Published: 23 March 2017

Citation:

Lerario AM, Finco I, LaPensee $C$ and

Hammer GD (2017) Molecular

Mechanisms of Stem/Progenitor Cell Maintenance in the Adrenal Cortex.

Front. Endocrinol. 8:52.

doi: 10.3389/fendo.2017.00052

\section{Molecular Mechanisms of Stem/ Progenitor Cell Maintenance in the Adrenal Cortex}

\author{
Antonio Marcondes Lerario ${ }^{1}$, Isabella Finco ${ }^{1}$, Christopher LaPensee ${ }^{1}$ and \\ Gary Douglas Hammer, $1,2,3 *$
}

'Department of Internal Medicine, Division of Metabolism, Endocrinology, and Diabetes, University of Michigan, Ann Arbor, MI, USA, ${ }^{2}$ Endocrine Oncology Program, Comprehensive Cancer Center, University of Michigan, Ann Arbor, MI, USA,

${ }^{3}$ Center for Organogenesis, University of Michigan, Ann Arbor, MI, USA

The adrenal cortex is characterized by three histologically and functionally distinct zones: the outermost zona glomerulosa $(\mathrm{zG})$, the intermediate zona fasciculata, and the innermost zona reticularis. Important aspects of the physiology and maintenance of the adrenocortical stem/progenitor cells have emerged in the last few years. Studies have shown that the adrenocortical cells descend from a pool of progenitors that are localized in the subcapsular region of the $z G$. These cells continually undergo a process of centripetal displacement and differentiation, which is orchestrated by several paracrine and endocrine cues, including the pituitary-derived adrenocorticotrophic hormone, and angiotensin II. However, while several roles of the endocrine axes on adrenocortical function are well established, the mechanisms coordinating the maintenance of an undifferentiated progenitor cell pool with self-renewal capacity are poorly understood. Local factors, such as the composition of the extracellular matrix (ECM) with embedded signaling molecules, and the activity of major paracrine effectors, including ligands of the sonic hedgehog and Wnt signaling pathways, are thought to play a major role. Particularly, the composition of the ECM, which exhibits substantial differences within each of the three histologically distinct concentric zones, has been shown to influence the differentiation status of adrenocortical cells. New data from other organ systems and different experimental paradigms strongly support the conclusion that the interactions of ECM components with cell-surface receptors and secreted factors are key determinants of cell fate. In this review, we summarize established and emerging data on the paracrine and autocrine regulatory loops that regulate the biology of the progenitor cell niche and propose a role for bioengineered ECM models in further elucidating this biology in the adrenal.

Keywords: adrenal cortex, paracrine signaling, stem cells, organogenesis, extracellular matrix, tissue homeostasis

\section{INTRODUCTION}

In vertebrates, adrenal steroid hormones are effectors of different adaptive responses to oscillations in the organism's internal and external environment, broadly referred as stress. Adrenal steroid hormones serve to modulate a wide range of processes that are central to physiologic response to 
stress, including energy metabolism, immune response, electrolyte homeostasis, and fluid balance. The three main classes of adrenal steroid hormones, mineralocorticoids, glucocorticoids, and androgens, are produced by the adrenal cortex under the tight regulation of distinct and independent endocrine regulatory loops: the renin-angiotensin-aldosterone system (RAAS) and the hypothalamus-pituitary-adrenal (HPA) axis. The ability of the adrenal gland to respond independently to these endocrine signals is dependent upon subpopulations of steroidogenic cells with distinct morphological and functional characteristics that are localized in specific concentric compartments (zones) of the cortex. In humans, three histologically distinct zones are evident: the outermost zona glomerulosa (zG), the intermediate zona fasciculata $(\mathrm{zF})$, and the innermost zona reticularis $(\mathrm{zR})$, which are responsible for the production of mineralocorticoids, glucocorticoids, and androgens, respectively (1). Although the morphological and physiological aspects of the adrenal cortex have been relatively well characterized, the regulatory mechanisms responsible for the establishment and maintenance of the three zones are not fully understood.

In the last few years, sophisticated molecular techniques, such as lineage tracing, and genetically modified animals have significantly contributed to our understanding of the embryonic development and homeostasis of the adrenal cortex, illuminating key molecules and signaling pathways that are implicated in these processes (discussed below in Sections "Progenitor Populations in the Adrenal Gland" and "Signaling Pathways and Adrenal Progenitors"). Accordingly, the Wnt and the hedgehog pathways have emerged as major paracrine factors that regulate both organogenesis and homeostasis of the gland. Both are essential for the establishment and maintenance of an undifferentiated population of steroidogenic precursor cells in the periphery of the organ that continuously replenish the cortical cells of the three zones throughout life (discussed below in Sections "Progenitor Populations in the Adrenal Gland" and "Signaling Pathways and Adrenal Progenitors"). While the effectors of the RAAS and the HPA axis [angiotensin 2 and adrenocorticotrophic hormone $(\mathrm{ACTH})$, respectively] are considered primary endocrine mediators that promote activity of adrenocortical steroidogenic cells (2-4), recent data support that the microenvironment, comprised of the extracellular matrix (ECM), its associated proteins, and several paracrine and autocrine factors, are also major determinants of cell behavior and fate (discussed below in Sections "Signaling Pathways and Adrenal Progenitors" and "The Adrenocortical Progenitor Niche"). Emerging data support an important role for non-steroidogenic/mesenchymal-like cells that lie in the adrenal capsule in the maintenance of the adrenocortical progenitor pool (5-8). This review focuses on the role of microenvironmental factors and signaling pathways that contribute to the maintenance of the adrenal cortex. We will discuss emerging data on the role of specific paracrine and autocrine loops between capsular/stromal cells and cortical cells in establishing a specialized microenvironment that supports and maintains the adrenal progenitors throughout the life-the niche - and how this signaling contributes to the anatomical and functional zonation of the adrenal cortex.

\section{DEVELOPMENTAL ORIGINS OF THE ADRENAL CORTEX}

The adrenal cortex originates from cells of the celomic epithelium, which in the mammalian embryo is composed of a single squamous cell layer that covers the external surface of the viscera and the inner surface of the body wall. Around embryonic day 9.5 (E9.5) in mice, and during the fourth to sixth weeks of human gestation, a thickening of the celomic epithelium between the urogenital ridge and the dorsal mesentery forms the adrenogonadal primordium (AGP). At the eighth week of human gestation (E10.5 in mice), the AGP divides into dorsomedial and ventrolateral portions, giving rise to the adrenal and gonadal primordia, respectively $(1,9-11)$.

Between the weeks 8 and 9 of human gestation (E13 in mice), the adrenal primordium is invaded by cells of the neural crest that coalesce centrally to form the adrenal medulla (12). Subsequently, the adrenal primordium is surrounded by mesenchymal cells, which will ultimately form the adrenal capsule (13). At this point, compartmentalization of the adrenal cortex into two structurally distinct areas is evident: a central area, comprised of large polyhedric eosinophilic cells referred as the "fetal zone," and a peripheral zone adjacent to the newly formed capsule comprised of small and basophilic cells, referred to as "the definitive zone." While in mice this compartmentalization is subtle, in humans, the fetal zone predominates over the definitive zone, constituting up to $80 \%$ of the adrenal mass by the end of the gestation $(9,14)$. In addition, ultrastructural studies in humans have demonstrated the presence of a third zone, referred as the "transitional" or "intermediate zone," which has intermediate morphologic characteristics between the fetal and the definitive zones (9). It has been suggested that after mid-gestation the transitional zone has the capacity to synthesize cortisol $(9,15)$. By the week 30 of human gestation, the definitive and the transitional zones have morphological features that resemble the adult $\mathrm{zG}$ and $\mathrm{zF}$, respectively (16). In humans, the fetal cortex starts to regress by apoptosis soon after birth, completely disappearing after a few weeks (9). In mice, definitive evidence about the presence of a transient fetal zone was provided by the identification of the fetal adrenal-specific enhancer (FAdE), which is only active during early fetal development (see below). The differentiation process of the human adrenal cortex continues until the onset of puberty, when the definitive cortex completes its organization into the three distinct histologic zones that characterize the adult cortex of human and higher primates (14). While the $\mathrm{zG}$ and the $\mathrm{zF}$ are evident at birth, the androgen-producing $z R$ only starts to form a few years later, marking the onset of the adrenarche, which is the earliest stage of sexual maturation and a precursor of puberty (17).

A transcription factor critical for adrenocortical development and homeostasis is steroidogenic factor 1 (SF1, also known as adrenal four-binding protein or nuclear hormone receptor Ad4BP, encoded by the gene NR5A1). All cells that belong to steroidogenic lineages of the adrenal and gonads express SF1, including subpopulations of long-term retained progenitor cells in each organ $(8,18)$. Therefore, SF1 expression defines the identity of these cells and commitment to steroidogenic 
differentiation $(14,19,20)$. The expression of SF1 is detectable early in fetal life, between the AGP formation and the ultimate establishment of the adrenal primordium $(14,18)$. Genetic loss of $N r 5 a 1$ or its upstream transcriptional regulators $P b x 1, W t 1$, and Cited2, interferes with AGP formation leading to various degrees of adrenal hypoplasia in mice $(12,14,21-23)$. While Nr5a1 is continuously expressed from the time of adrenal primordium formation throughout the adult life, during embryonic stages and early fetal life in mice, the Nr5a1 expression is driven by the fetal adrenal-specific enhancer (FAdE), which becomes inactive when the definitive cortex forms, suggesting that distinct mechanisms sustain Nr5al expression in the fetal and in the definitive cortex (14).

While the enhancer that is responsible for initiation and maintenance of Nr5al expression in the definitive zone is currently not known, lineage-tracing experiments performed by Zubair et al. have shown that FAdE-driven-Ad4bp-expressing cells are indeed precursors of most, if not all, Sf1-expressing cells of the definitive cortex (14). It has since been demonstrated that after extinguishing FAdE-dependent SF1 expression, some cells become embedded within the coalescing capsule and later reemerge as FAdE-independent SF1-expressing cells during the formation of the definitive cortex (24).

Steroidogenic factor 1 not only defines the identity/specification of the cells of the definitive cortex but also serves as a key regulator of hormone-dependent steroidogenesis, the hallmark of a differentiated adrenocortical cell. In this regard, the effects of ACTH on differentiation and steroidogenesis are partially mediated by an SF1-induced transcription of steroidogenic enzymes that defines a cortisol-producing cell (25). It remains unclear, however, how a subpopulation of SF1-expressing cells are spared from the pro-differentiation effects of ACTH, preserving their undifferentiated state. One clue to such regulation comes from studies of DAX1, an atypical nuclear receptor that is encoded by the gene NROB1 and expressed preferentially in the peripheral/subcapsular cortex. DAX1 functions as a repressor of SF1-mediated transcription and has been shown to have an important role in the maintenance of the undifferentiated state (lack of steroidogenesis) of the adrenocortical progenitor population (26). Studies examining the consequences of genetic loss of DAX1 in the adrenal revealed an unexpectedly hyper-functional $\mathrm{zF}$ in younger mice, characterized by an increase in cell proliferation and steroid production. Surprisingly, as the animals aged, they developed adrenal hypofunction consistent with an abnormal premature differentiation of the progenitor cell pool that ultimately resulted in its exhaustion $(27,28)$. In the next section, we will briefly summarize studies that have begun to explore the molecular and cellular processes that underlie the homeostasis of the progenitor cell population.

\section{PROGENITOR POPULATIONS IN THE ADRENAL GLAND}

One of the first reports regarding adrenal regeneration in rats describes the restoration of the adrenal cortex 6 weeks after unilateral adrenal enucleation, a process that involves the removal of the inner content of the adrenal gland (including the medulla), while leaving the capsule and underlying subcapsular cells intact. This observation suggested the presence of an adrenocortical stem and/or progenitor cell population located in the periphery of the adrenal gland (29). The notion of a renewing progenitor population in the adrenal cortex was corroborated by the observation that transplants of bovine adrenocortical cells underneath the kidney capsules of adrenalectomized immunocompromised mice can give rise to adrenocortical tissue with steroidogenic properties $(30,31)$.

The presence of a progenitor cell population in the periphery in the adrenal gland that gives rise to all the differentiated cell types within the different cortical zones is consistent with a homeostatic model of centripetal migration and differentiation. This idea was first hypothesized in the 19th century, based on histological observations of gradual changes in morphology observed in cells between the capsule and the medulla $(32,33)$ [reviewed in Ref (34)]. Over the years, different studies have shown that, under physiological conditions, proliferating cells are located preferentially in the outermost layers of the cortex, in the subcapsular region $(35,36)$. Also, it has been demonstrated that peripheral cortical cells are centripetally displaced until they reach the cortical-medullary boundary and become apoptotic $(35,37)$. Moreover, studies performed in chimeric and transgenic mosaic rats and mice have shown a radial variegated pattern of the reporters extending from the outer cortex to the cortico-medullary boundary. This observation is consistent with a peripheral clonal origin (38-40). Definitive genetic evidence for a centripetal conversion of adrenocortical cells between concentric zones was finally provided by cell-lineage tracing $(8,41)$. In one of these studies, transgenic mice were created with a Cre recombinase gene inserted at the Cyp11b2 locus, in which Cre was expressed only in terminally differentiated $z G$ cells (41). When these mice were crossed with mice expressing the $R 26 R^{m T / m G}$ reporter, GFPpositive cells that occupied the $\mathrm{zG}$ upon Cyp11b2-Cre expression, eventually populated the entire cortex. Over time, an increasing number of centripetally located Cyp11b1-expressing cells were found to express GFP, indicating that peripheral $\mathrm{zG}$ cells underwent lineage conversion to more centripetal zF cells. In 12-week old mice, nearly the entire cortex was comprised of GFP-positive cells. Although these existing data strongly support the existence of a progenitor population localized in the periphery of the gland that gives rise to all the steroidogenic cells types of the cortex through a process of centripetal displacement/migration and differentiation, the molecular mechanisms that govern this process are not completely understood.

Further studies have provided clues on the molecular fingerprint of the progenitor cell populations and the signaling pathways that regulate their renewal and differentiation. Specific paracrine/autocrine signaling pathways are activated in zonally restricted patterns that reflect the different cell subpopulations that are hypothesized to play an active role in organ homeostasis. The most important and well characterized are the Wnt and the hedgehog pathways. Additionally, a cross-talk between cortical cells and capsular stromal cells regulates the activity of these pathways. Below, we briefly summarize these findings. 


\section{SIGNALING PATHWAYS AND ADRENAL PROGENITORS}

\section{Wnt Signaling Pathway}

The mammalian wingless-type MMTV integration site (Wnt) signaling pathway is one of the most studied pathways in developmental biology, playing important roles in organogenesis, homeostasis, and stem cell biology (42). Wnt ligands represent a large family of highly conserved morphogens that are characterized by repetitive cysteine residues. Secreted Wnt ligands bind to receptors of the Frizzled and lipoprotein receptor-related protein families on the cell surface. Through several cytoplasmic components, the signal is either transduced through $\beta$-catenin, which enters the cell nucleus and complexes with T-cell factor/ lymphocyte enhancer factor (TCF/LEF) family of transcription factors to activate transcription of Wnt target genes (canonical pathway), and/or activates the non-canonical Wnt pathway to regulate planar cell polarity and calcium signaling (42). In the mouse adrenal gland, $\beta$-catenin expression is first observed at E12.5 in Sf1+ cells of the definitive cortex in a scattered fashion beneath the newly formed capsule (43). After E18.5 and throughout life, $\beta$-catenin protein expression becomes more enriched in cells of the $\mathrm{zG}$, which have also been demonstrated to bear active canonical Wnt signaling $(43,44)$.

Canonical Wnt signaling plays several roles in the adrenal cortex. Recent evidence demonstrates that the population of Wnt-responsive cells is heterogeneous and contains small clusters of Shh-producing cells (considered to be adrenal progenitors, as it will be discussed later) and separate differentiated Cyp11b2expressing cell clusters (44). Interestingly, despite the well-known role of Wnt signaling pathway in promoting cell proliferation in a variety of organ systems, the Wnt-responsive cells do not appear to be heavily proliferating, implying that any role of Wnt signaling in adrenal homeostatic growth might involve a potential cell nonautonomous mechanism (44).

The Wnt pathway is essential for the establishment and maintenance of the subcapsular progenitor cell population. However, it does not appear to play a role in the early formation of the AGP since expression of Ctnnb1 is first detectable in mesothelial cells overlying the indifferent gonad at around E11.5 and in the adrenal primordium at around E12.5, following their separation from the AGP $(43,45)$. Studies performed in a Nr5a1/Cre-mediated Ctnnb1 conditional knockout mouse model (Ctnnb1tm $2 \mathrm{kem}$ mice crossed into Sf1/Cre-high mice), in which canonical Wnt signaling to adrenal primordium SF1-expressing cells from around E12.5 is reduced or absent reveal a marked decrease in cortical cell proliferation which ultimately results in the complete regression of the adrenal gland by E18.5, despite normal formation of the adrenal primordium at earlier time points (43, 46). Loss of $\beta$-catenin in approximately $50 \%$ of Sf1-expressing cells and hence a resultant $\sim 50 \%$ decrease in $\beta$-catenin-mediated Wnt signaling (induced by a low efficiency Sf1/Cre-low driver that allows for a subset of cells to escape recombination) results in a histologically normal adrenal through 15 weeks of age, after which the adrenal cortex undergoes progressive thinning over time and ultimate adrenal failure $(43,46)$. Consistent with a primordial role of the Wnt signaling in maintaining the progenitor cell population, it has been demonstrated that NrOb1 (Dax1) is a transcriptional target of $\beta$-catenin, suggesting that both proteins synergistically act to maintain the undifferentiated state that characterizes the progenitor cell population (28). Together, these evidences suggest that canonical Wnt signaling has a role in establishing and maintaining a pool of adrenocortical progenitors throughout life.

\section{Hedgehog Signaling Pathway}

The hedgehog signaling pathway $(\mathrm{Hh})$ is a conserved evolutionary pathway that is essential for embryonic development and adult tissue maintenance, renewal, and regeneration. Three secreted hedgehog proteins have been described: sonic hedgehog $(\mathrm{SHH})$, desert hedgehog, and Indian hedgehog. These proteins function in a concentration- and time-dependent fashion, controlling several processes ranging from survival and proliferation to cell fate specification and differentiation (47).

$\mathrm{Shh}$ is the only Hh family member that is present in the murine adrenal gland, being detected as early as E12.5 and later expressed in a restricted manner in a subpopulation of cells in the outer $\mathrm{zG}$ (8). These cells are Sf1-positive and do not express Cyp11b2 or Cyp11b1, the enzymes necessary for terminal reactions that lead to aldosterone and corticosterone production, respectively. While in the mouse adrenal the Shh+ cells are localized in clusters under the capsule, in the rat these cells form a continuous layer localized between the $\mathrm{zG}$ and the $\mathrm{zF}$, known as the undifferentiated zone (zU) (48).

Lineage-tracing studies that mark all Shh-expressing cells and their descendants reveal that, by postnatal day 12 (P12), virtually all cells of the cortex are derived from Shh-expressing cells, consistent with a role for Shh in the peripheral stem/progenitor cells (8). Studies utilizing an inducible Shh-Cre recombinase have demonstrated that shortly after recombination in adult mice, Shhexpressing cells, and their immediate descendants are restricted to the periphery of the cortex. Over time, these cells and their descendants form centripetally expanding radial stripes, supporting the hypothesis that the Shh-expressing cells are a progenitor population that gives rise to all other cortical cell populations (8). BrdU-labeling experiments carried out on rat adrenals identified two sites of proliferation in the outer $\mathrm{zF}$ and inner $\mathrm{zU}$ and between the $\mathrm{zG}$ and $\mathrm{zU}$, suggesting that cell proliferation at the periphery of the $\mathrm{zU}$ provides cells to both $\mathrm{zG}$ and $\mathrm{zF}$ (36). However, the proliferative capacity of these cells is more consistent with their identification as progenitors rather than as stem cells as suggested by the authors. Another study on mouse adrenocortical cell proliferation used BrdU pulse-chase labeling to identify a small population of quiescent non-steroidogenic cells located in the outer cortex that may represent a quiescent progenitor population, which is prompted to divide following ACTH stimulation (35). Additionally, this study suggested that two distinct subpopulations of rapidly cycling cells emerged from the progenitor population-the first constituted by cells that proliferate in response to ACTH and migrate inwards and the second constituted by cells that migrate outwards and are less responsive to ACTH. The authors have suggested that these distinct subgroups of cells are committed transient-amplifying cells that are responsible for the maintenance of the $\mathrm{zF}$ and $\mathrm{zG}$, respectively (35). Interestingly, 
another study has shown that Cyp11b2-expressing cells in the zG derived from the Shh-expressing cells undergo lineage interconversion, differentiating into Cyp11b1-expresing cells in the $\mathrm{zF}$ as they migrate inwards, suggesting that cells from both zones are in fact derived from the same lineage (41).

In addition to serving as a progenitor cell population in the cortex, Shh-positive cells presumably signal to Gli1-expressing cells that lie within the capsule $(48,49)$. Interestingly, the capsular Gli1-expressing cells are a mesenchymal-like population that do not express Sf1 (Gli1+/Sf1-) but descends from the fetal FAdEutilizing Sf1+ cells of the adrenal primordium (24). The fate of the descendants of these Gli1-expressing cells has been investigated in a transgenic mouse model with an inducible Gli1-CreERT2 allele. It has been demonstrated that during adrenal development, Gli1+ capsular cells behave as stem or precursor cells since they give rise to Sf1+ cells of the early definitive cortex that later become the Sf1+/Shh+ progenitor cell pool (8).

\section{Other Signaling Pathways}

In addition to the Gli+/Sf1 - cell population, other mesenchymal-like cell lineages have also been identified in the capsule and the stroma. These cells may also have important roles in the adrenal gland maintenance. Bandiera and colleagues observed a long-retained pool of cells expressing the Wilms tumor protein homolog (WT1) in the adrenal capsule that originates from capsular mesenchymal cells and is characterized by AGP features (50). WT1 is a transcriptional regulator that has important roles in organogenesis of different organs, including the adrenals and gonads. Using a Wt1-Cre recombinase line crossed with a reporter line, Bandiera et al. demonstrated that WT1-expressing cells could give rise to steroidogenic cortical cells in the adult adrenal and the Gli1+ population as well, lending support for a role for WT1 in the activation of Gli1 transcription.

Wood et al. identified a population of cells in the mouse adrenal that starts to express the transcription factor 21 (Tcf21, also known as Pod1/capsuling/epicardin) at E9.5 onward. After E14.5, Tcf21 expression becomes predominately restricted to the capsule and further diminishes over time, leaving only a small population of capsular Tcf $21+$ cells through adulthood. Lineage-tracing experiments revealed that before adrenal encapsulation, $T c f 21$-expressing cells and/or their descendants give rise to both non-steroidogenic capsular cells and steroidogenic cortical cells. On the other hand, the population of Tcf21-expressing capsular cells only gives rise to a population of Sf1- stromal cells that express collagen, desmin, and Pdgfr $\alpha$ and persist throughout adult life within the cortex (24).

Taken together, these studies provide evidence that the capsule is a complex niche comprised of multiple long-term retained cell lineages. The roles of each of these populations in the adult adrenal remain unknown, but recent evidence suggests that signaling coming from the capsule is required for the long-term maintenance of the adrenocortical progenitor cells.

\section{THE ADRENOCORTICAL PROGENITOR NICHE}

The proper balance of progenitor proliferation and differentiation is crucial, as dysregulation of the mechanisms that regulate the differentiation, proliferation, and self-maintenance of progenitor cells throughout life can result in organ failure. Stem and progenitor cells from different organs and tissues are embedded within a specialized microenvironment, termed the niche. Niches are protective locations that support stem cell residence and maintenance. Several components of the niche have been identified, including bioactive compounds, such as Wnt ligands, growth factors [e.g., fibroblast growth factors (FGFs) and epidermal growth factor], chemokines, and a distinct ECM composition that sequesters growth factor signaling and spatially restricts cell movement for appropriate cell-cell interactions. While well-defined niches characterized in different organs vary in size and complexity, most are maintained by a small set of fundamental regulatory signaling loops (51). Although several studies have revealed the importance of these signaling pathways in the adrenal biology as coordinators of stem/progenitor cell specification and differentiation, the formal structural and molecular definition of an adrenocortical progenitor niche remains elusive (52). ECM components are predicted to provide additional structural context to zone-specific signaling pathways discussed in the previous section. Below, we discuss these regulatory mechanisms in further details.

\section{Components of the Adrenocortical Niche Soluble Factors \\ Wnt Ligands}

As previously discussed, the canonical Wnt $/ \beta$ catenin signaling pathway is considered to be a crucial pathway for the maintenance of the subcapsular stem/progenitor pool $(44,46,53)$. While the source and the contribution of different Wnt ligands to Wnt signaling are not currently known, previous observations based on adrenal tumors expression profiles, human clinical syndromes, and mouse models suggest that WNT4 is an important Wnt regulatory paracrine factor in the adrenal cortex. In humans, WNT4 mutations underlie the defects in Serkal syndrome, an autosomal recessive disorder characterized by multiple malformations including adrenal hypoplasia and male-to-female sexual reversion (54). In mice, while Wnt 4 expression is observed in the developing adrenal glands as early as E11.5, by E14.5 it is restricted to the outer cortex $(46,55)$. Additionally, a mouse model of Wnt 4 inactivation suggests that this ligand is required for proper $\mathrm{zG}$ differentiation and aldosterone production. In these mice, genetic loss of Wnt4 decreases Cyp11b2 expression, leading to a diminished production of aldosterone (55). Interestingly, the anterior tips of the developing gonads of these mice exhibit a steroidogenic enzyme expression pattern similar to adrenocortical cells, suggesting an abnormal differentiation process or a defect in adrenal cell specification during the separation of the AGP $(55,56)$.

WNT4 is a known transcriptional target of $\mathrm{Wnt} / \beta$ catenin signaling (55). In the adrenal cortex, WNT4 expression is restricted to the $\mathrm{zG}$, precisely where canonical Wnt pathway is known to be active. Additionally, according to our own analysis on a recently published molecular profiling study on adrenocortical carcinomas (57), samples with activating exon 3 CTNNB1 mutations exhibit increased expression of WNT4 in comparison to samples without somatic alterations in components of the Wnt pathway (fold change $=17.5$, FDR-adjusted $p$-value $<0.001$ ). More recently, it has been demonstrated that the expression levels 
of canonical Wnt target genes are significantly reduced in the adrenals of a mouse model of Sf1-Cre mediated Wnt4 knockout (Sf1:Cre; Wnt4Fl/Fl) (58). Interestingly, it has also been shown that the activation of the protein kinase A pathway enables a zG-tozF lineage conversion by antagonizing canonical Wnt signaling, which is partially mediated by repression of Wnt4 expression (58). Together, these data support a model whereby WNT4 serves as an autocrine activator of Wnt signaling, amplifying canonical ( $\beta$ catenin-dependent) Wnt activation within the $z G$, which is essential for proper zonation. However, whether WNT4 downstream signaling also induces a non-canonical ( $\beta$ cateninindependent) effect is currently not known. In other systems, WNT4 is described preferentially as a non-canonical ligand (59, $60)$. Last, the roles and the sources of other Wnt ligands that are expressed in the adrenal are yet to be determined.

\section{Other Wnt Pathway-Related Soluble Factors}

Bone Morphogenetic Protein-4 (BMP4) is a ligand of the TGF- $\beta$ superfamily that plays essential roles in embryonic development, stem cell biology, and tissue regeneration (61). Recently, Rege et al. have demonstrated that this protein, its receptors, and downstream molecules are expressed and have functional roles in the human adrenal cortex and in the H295R adrenocortical carcinoma cell line. Interestingly, mRNA expression of BMP4 follows a zonal distribution gradient, with the highest levels in the $\mathrm{zG}$, suggesting that BMP4 is a Wnt target gene. In vitro, BMP4 actively inhibits the expression of 17,20-lyase and DHEA secretion, possibly serving to prevent a $\mathrm{zR}$ fate (62). Consistent with the observed zonal distribution in the adrenal cortex, $B M P 4$ has been reported as a Wnt target gene in a colorectal cancer cell line (63). Moreover, according to our own analysis on two independent datasets $(57,64), B M P 4$ mRNA is upregulated in ACC samples with nuclear immunostaining for $\beta$-catenin or with an activating mutation of CTNNB1 in comparison to those with membranous immunostaining or wild-type for CTNNB1 somatic mutations (fold change $>3.21-6.76$, FDR-adjusted $p$-value $<0.001$ ). These observations suggest that BMP4 is a paracrine factor regulated by the Wnt pathway that may have a role in functional zonation by inhibiting a $\mathrm{zR}$ fate.

Coiled-coil domain containing 80 (CCDC80) has recently been described as a novel Wnt target gene in the adrenal cortex. In situ hybridization has shown that it is expressed in cells within the zG. Functional studies have shown that CCDC80 decreases steroidogenesis in vitro, suggesting, as for $\mathrm{BMP} 4$, a role in cell differentiation or fate. The molecular pathway by which CCDC80 regulates steroidogenesis is yet to be determined in the adrenal gland (44). In the chick embryo, the CCDC80 homolog equarin regulates FGF signaling by increasing its local availability and by facilitating the interactions of FGF ligands with FGF receptors and proteoglycans (65). Further studies in CCDC80 null mice aiming to characterize the overall mechanism of action of CCDC80 in the adrenal gland are ongoing.

\section{Sonic Hedgehog}

Sonic hedgehog-expressing cells serve as a bona fide progenitor population that contributes to the adrenal cortex homeostasis in adult life, as previously described. Mice with global genetic deletion of Shh exhibit severe adrenal hypoplasia during embryonic development due to a reduction in both cortical and capsular cell proliferation $(8,66,67)$. However, these animals also have severe malformations in other organs, including pituitary defects that impair ACTH production, making the adrenal phenotype difficult to interpret. Moreover, targeted deletion of Shh in Sf1-expressing cells in mice also causes adrenal abnormalities, indicating that $\mathrm{Shh}$ is indeed essential for intrinsic (ACTHindependent) adrenal development. While AGP separation, neural crest migration, and encapsulation occur normally, these animals have a hypoplastic adrenal cortex and diminished mitotic activity by E13.5. As age increases, progressive cortical thinning with an apparent defect in steroidogenesis is observed as reflected by a compensatory increase in ACTH levels. Also, an overall thinner capsule is also seen (66). The mechanisms by which Shh deficiency causes this capsular phenotype are not known, but is predicted to result from a defective cortical Shh signaling to the capsular Gli1-expressing cells.

Shh is a secreted ligand that binds to the cell-surface receptor patched homolog 1 (Ptch1). Shh binding relieves Ptch1-mediated inhibition of Smoothened homolog (Smo). Smo stimulates intracellular downstream Shh signaling that, when activated, inhibits the otherwise proteolytic degradation of Gli transcription factors, resulting in Gli-mediated transcriptional activation of Hh target genes $(8,47,66,67)$. Whether a secreted factor produced by Shhresponsive Gli+ capsular cells is required for maintaining the subcapsular progenitor population is currently unknown. Together, these observations indicate that the Shh-expressing subcapsular progenitor cells and the capsular Gli-expressing cells are integral components of the adrenocortical progenitor cell niche.

\section{Fibroblast Growth Factors}

The FGFs are a family of secreted signaling proteins that bind to a subclass of membrane-bound tyrosine kinase-coupled receptors (FGFRs 1-4) and intracellular non-signaling proteins (iFGFs) that work as cofactors for other membrane-associated proteins. With few exceptions, FGFs are ubiquitous paracrine/autocrine factors with essential roles in embryogenesis, organogenesis, and tissue homeostasis. FGFs regulate fundamental cellular processes, including proliferation (both promoting and inhibiting), survival, differentiation, migration, and metabolism. FGFs routinely bind to heparin sulfate proteoglycans, which limit their diffusion through the ECM and serve as cofactors that regulate FGF specificity and affinity to different types of FGFRs $(68,69)$.

Early studies have demonstrated that FGFs exhibit a potent mitogenic effect both in the murine-derived Y1 adrenocortical cell line and primary cultures of bovine and human adrenocortical cells. Interestingly, this effect can be antagonized by ACTH, which promotes cell differentiation by inducing cell cycle arrest and steroidogenesis in vitro (70-74). In vivo, different combinations of FGF ligands and receptors are expressed in the adrenal capsule and cortex, consistent with a proposed role in homeostasis. RT-PCR analysis from laser capture microdissected adrenals from E15.5 mouse embryos have shown that Fgf1, Fgf2, and Fgf9 are the only FGF ligands that are expressed in the embryonic adrenal gland. While Fgf1 is expressed in the cortex, Fgf2 and Fgf9 are expressed preferentially in the capsule. Additionally, 
Fgfr1-IIIc, Fgfr2-IIIb, and Fgfr2-IIIc are expressed in cells of both the capsule and the cortex. Interestingly, the cortical cells that express Fgfr2 are the also Shh-positive $(48,75,76)$.

The importance of FGF signaling in adrenal maintenance has been revealed through several in vivo studies. FGF2 encapsulated in poly-lactic-co-glycolic acid enhances the growth of adrenocortical cells implanted under the kidney capsule of mice by fivefold to eightfold (74). Additionally, engineered deletion of the FGF ligand, FGF2 or the FGF receptor Fgfr2, results in various degrees of adrenal hypoplasia after birth. The global Fgfr2-IIIb knockout results in embryonic lethality due to severe malformations, including adrenal hypoplasia (7). The same adrenal phenotype was recapitulated by a $S f 1$-driven specific knockout of both Fgfr2-IIIb and Fgfr2-IIIc (77). Evaluation of the embryonic adrenal gland of Fgfr2-IIIb global knockout mice at E15.5 revealed a marked capsular defect, characterized by thickening and disorganization of the mesenchymal capsule, with increased mitotic activity and increased number of Gli1-positive cells. Meanwhile, the underlying cortex was hypoplastic with a decrease in both steroidogenic differentiation and mitotic activity. An unexpected, decrease in capsular delta-like protein 1 (Dlk1) suggests that, together with Shh and FGFs, Dlk1 is a mediator of the proposed homeostatic cross-talk between cortical and capsular cells (75).

\section{Delta-Like Protein 1 (DLK1)}

Delta-like protein 1 (also known as preadipocyte factor 1-Pref1) is a paternally expressed imprinted gene that encodes an epidermal growth factor repeat-containing transmembrane protein. Dlk1 is cleaved by the TNF-alpha-converting enzyme (TACE or ADAM17) to generate a soluble, secreted, and biologically active protein $(78,79)$. In adipose tissue, DLK1 negatively regulates proliferation and terminal differentiation of adipocyte progenitors (80-83). Mechanistically, DLK1 interacts with fibronectin and facilitates downstream integrin signaling, which includes MEK/ ERK activation (80). While the human adrenal cortex expresses high levels of the DLK1 transcript (the highest levels among all human tissues according to the GTEx portal database), little is known about its downstream signaling and overall function in adrenocortical cells (84). However, in vivo studies in rat reveal that $D l k 1$ expression is markedly decreased in the regeneration process following enucleation, suggesting a role in adrenal remodeling and zonation. The Dlk1 expression is restricted to a subcapsular population in the rat $\mathrm{zU}(6,85,86)$. Indeed, the Dlk1+ cells do not express Cyp11b1 and are rarely positive for Cyp11b2. They do, however, express Shh, indicating that they are indeed the progenitor population $(48,87)$. A low-sodium diet induces a marked downregulation of both Dlk1 and Shh, with a proportional increase in the expression of Cyp11b2. Blocking the RAAS with captopril induces the opposite effect-expansion of Dlk1 and Shh-expressing cells. Additionally, a population of capsular cells responds directly to Dlk1 signaling by increasing the levels of both p-ERK and Gli1, consistent with a role in regulating hedgehog signaling (6). These results predict that in the rat adrenal, Dlk1 is expressed by the cortical progenitor cell population and acts in concert with Shh to activate capsular Gli1, modulating differentiation, remodeling, and zonation (6). However, it should be noted that these conclusions are based on studies in rat, which express Dlk1 in the subcapsular cells whereas, in mice, Dlk1/ Pref1 is expressed in the capsule $(6,75)$.

\section{R-Spondin Family Member 3 (RSPO3)}

$\mathrm{R}$-spondins are secreted proteins that have been recently described as important positive regulators of the canonical Wnt pathway (88). R-Spondins are paracrine factors that exhibit a very low diffusion gradient since these proteins firmly binds to certain ECM components such as syndecan-4, remaining close to its secretory source (89). In organs, such as the liver and the gastrointestinal tract, RSPO3 gradients are a critical determinant of regions of active canonical Wnt signaling, being a crucial regulator of the stem/progenitor cell compartment, cell differentiation, and functional compartmentalization (90). R-Spondins interact with members of the leucine-rich-repeat-containing G-protein-coupled receptor (Lgr), which have recently been described as surface stem cell markers (91). Clinical evidence suggests an important role of R-Spondins in stem cell biology and morphogenesis since inactivating mutations in R-Spondin genes are associated with syndromes characterized by stem cell failure and developmental abnormalities (89). The interaction of $\mathrm{R}$-Spondins with the Lgr receptors results in the inactivation of the U3-ubiquitin ligases RNF43 and ZNRF3, which are negative regulators of Wnt signaling by promoting internalization of the Frizzled receptors. Consequently, in the presence of R-Spondins, the Frizzled receptor will remain on the membrane allowing for Wnt signaling activation (91, 92). A recent paper explores the roles of R-Spondins in the regulation of the canonical Wnt signaling, functional zonation, and progenitor cell activity in the adrenal cortex (5). By using in situ hybridization, the authors demonstrated the expression of Rspo1 and Rspo3 in the adrenal capsule of the mouse from E12.5 onward. While Rspo1 colocalized with the Wt1 mesodermal-like expressing cells, Rspo3 was preferentially co-expressed with $\mathrm{Nr} 2 \mathrm{f2}$ and Gli1-expressing cells. Additionally, the mRNA abundance of Rspo3 was significantly higher than Rspo1. Interestingly, while the genetic loss of Rspo1 had no observable effects on the adrenals, loss of Rspo3 was associated with remarkable phenotypes. By using different crosses of a Rspo $3^{\text {fox }}$ allele and several CreERT drivers, the authors demonstrated that (a) loss of Rspo3 results in cortical atrophy both during development and postnatally; (b) these changes are accompanied by a dramatic decrease in canonical Wnt signaling, which results in loss of the expression of canonical Wnt target genes such as Axin2 and Wnt4; (c) loss of a functional zG, characterized by profound morphological changes and loss of expression of $\mathrm{zG}$ markers (while retaining $\mathrm{zF}$ differentiation); (d) loss of cortical Shh-expressing cells and capsular Gli1-expressing cells; and (e) a significant decrease in the mitotic activity of the cortex. The authors concluded that capsular-derived Rspo3 is a key regulator of both Wnt and Hedgehog signaling in the adrenal cortex, having determinant roles in the establishment and the maintenance of the stem/progenitor cell populations, and in functional zonation (5).

These above findings support a general model whereby several autocrine/paracrine mediators from different sources play regulatory roles in the major signaling pathways that control the progenitor cell compartment and fate determination in the 
adrenal cortex (Figure 1). Some are known to interact with ECM components, indicating that the ECM composition may play a role in these regulatory loops. However, several gaps in the knowledge about the role of the adrenal ECM in paracrine/ autocrine signaling and cell fate determination remain. In the following sections, we summarize the main findings that support a regulatory role for the adrenal ECM.

\section{The ECM and Associated Proteins}

The ECM is a three-dimensional meshwork of extracellular proteins and polysaccharides that supports cells in each tissue (93). Among its components are included fibrous proteins such as collagens, laminin, fibronectin, and several types of bioactive compounds, such as latent growth factors, enzymes, chemoattractants, and morphogens (94). Therefore, in addition to its role in providing the physical scaffold that shapes the different tissues in an organism, the ECM is a reservoir of several biologically active compounds of different sources that are delivered to the cells in a spatially controlled manner $(93,94)$. Cells attach to the ECM through a special type of membrane-bound adhesion molecule known as integrins, which are comprised of two interacting subunits. The vertebrate integrin family contains $18 \alpha$ and $8 \beta$ subunits that can assemble into 24 different receptor complexes, each with unique binding properties for different ECM components (93). In the context of the stem cell niche of a variety of organ systems, the interactions between ECM proteins and integrins are fundamental for establishing a balance between self-renewal and differentiation. By forming complexes with different membrane receptors and ECM components, integrins facilitate a strict compartmentalization of cellular responses to different factors on a cell-by-cell basis. Such highly precise control is fundamental to the process of asymmetric division, a fundamental characteristic of self-renewing cells. The complexes that contain integrins, ECM components, and other receptors induce the establishment of cell polarity, restricting fate-determinant molecules to one pole and directing the plane of cell cleavage in such a way that signaling molecules will be asymmetrically distributed between the daughter cells (95). In fact, certain types of integrins have been recognized as crucial for stem cell maintenance in different tissues (96). Supporting this observation, genetic ablation of $\beta 1$ integrin favors a symmetric pattern of cell division in the mammary stem cell niche, leading to exhaustion of the stem cell compartment (97). Finally, biophysical and biochemical properties of the substrate, such as shape, stiffness, and protein composition, can trigger different transcriptional programs that support either stem cell maintenance or differentiation $(98,99)$.

Despite the emerging importance of ECM in tissue homeostasis and stem cell biology, few studies have addressed its roles in the adrenal. Early studies in different species have shown that several ECM components and integrins follow a zonal distribution in the adrenal cortex $(100,101)$. Furthermore, in vitro studies on primary adrenal cultures grown on different substrates suggest that different ECM components affect cellular responses to ACTH. For instance, it has been demonstrated in primary cultures from human fetal adrenals that laminin exerts an inhibitory effect on basal and ACTH-induced steroidogenesis, and a positive effect on cell proliferation (102). On the other hand, collagen IV and fibronectin increased cortisol and DHEAS production, respectively (102). While collagen IV is expressed throughout the human fetal adrenal gland, laminin and fibronectin follow a

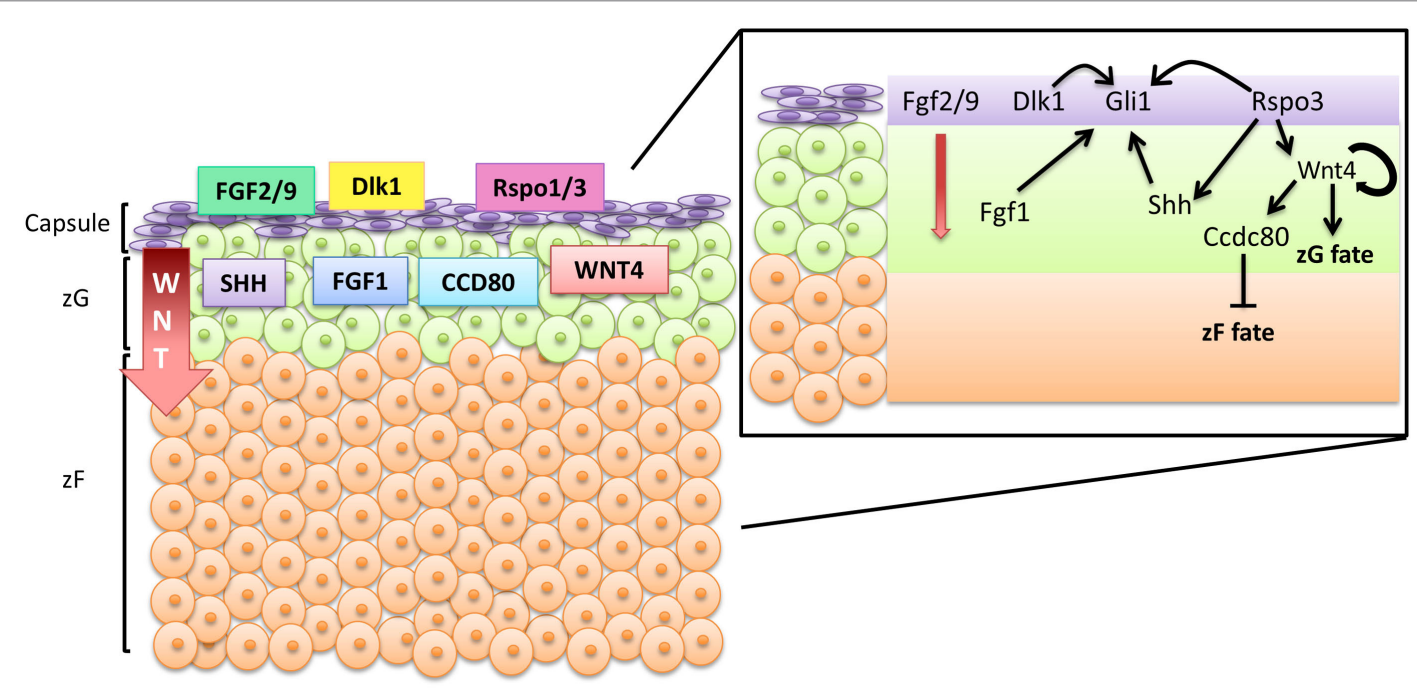

FIGURE 1 | Schematic figure representing paracrine signaling in the adrenal cortex. Adrenal zonation is established and maintained by a compartmentalized secretion of paracrine factors. The $z G$ is characterized by activation of canonical Wnt signaling, which is dependent on the presence of RSPO3 secreted by Gli1-expressing capsular cells. Wnt-expressing cells secrete other paracrine factors that regulate the differentiation of cortical cells. Wnt4 amplifies the activation of canonical Wnt signaling within the $\mathrm{zG}$, helping in maintaining the zonation. Ccdc80 and is a canonical Wnt target gene that prevents zF differentiation. By unknown mechanisms, a small proportion of Wnt-active zG cells, which is a long-living progenitor cell population, secretes Shh, which activates Gli1-dependent signaling on the capsular cells. Other paracrine factors, such as DIk1 and fibroblast growth factors, also have regulatory roles in the maintenance of the cortical progenitor cells, presumably by regulating Gli1 expression in the capsule. 
zonal distribution, being preferentially expressed in cells of the definitive and the fetal zones, respectively (101). Therefore, the differences in cellular responses in vitro induced by these different ECM components parallel the functional zonation observed in the fetal gland: laminin suppresses differentiation and promotes proliferation (consistent with the cellular phenotype of the newly forming definitive zone), collagen IV promotes HSD3B2 expression and cortisol production (resembling the fetal adrenal transitional zone), and fibronectin supports CYP17A1 expression and DHEAS production. Indeed, primary cultures from $\mathrm{zG}$ and $\mathrm{zF}$ cells from the adult rat adrenal grown on laminin-coated plates exhibited increased proliferation and reduced basal and ACTHstimulated aldosterone and cortisol production, respectively (103). Taken together, these results support the hypothesis that the ECM composition modulates cellular responses to hormone and growth factor stimulation, providing an additional mechanism by which the niche itself regulates the balance between self-renewal and differentiation.

\section{CONCLUDING REMARKS AND FUTURE PERSPECTIVES}

In the last decade, several important aspects of the physiology of the adrenal cortex have been characterized, including the developmental origins of the different progenitor populations and the molecular pathways that are essential for self-renewal, organ remodeling, and differentiation. Additionally, several paracrine/autocrine bioactive compounds that initiate and maintain these signaling pathways have been identified. However, while the progenitor niche populations of other tissues, such as the skin and the gastrointestinal tract, are clearly defined, the progenitor niche of the adrenal cortex is just beginning to be characterized. Many features of the molecular mechanisms that govern the fate of the adrenocortical progenitor cells are still unknown. As discussed in the previous sections, several studies involving transgenic animal models have illuminated important observations and concepts central to the field. However, these studies are complex and timeconsuming. Furthermore, studying such a small yet complex organ like the adrenal gland imposes additional challenges. In the near future, innovative techniques that allow investigators to engage in more complex in vitro studies have the potential to move the field forward greatly. Among these, organoid culture and engineered ECM are promising approaches.

Organoid culture has emerged in recent years as a valuable tool to study several aspects of stem cell biology, tissue morphogenesis, and lineage specification $(104,105)$. Organoids are self-organizing three-dimensional structures that are derived from stem cells and exhibit organotypic anatomic and functional features, including spatially restricted lineage commitment $(106,107)$. Organoids can be grown in vitro from pluripotent stem cells (embryonic stem cells and induced pluripotent stem

\section{REFERENCES}

1. Yates R, Katugampola H, Cavlan D, Cogger K, Meimaridou E, Hughes C, et al. Adrenocortical development, maintenance, and disease. Curr Top Dev Biol (2013) 106:239-312. doi:10.1016/B978-0-12-416021-7.00007-9 cells) or organ-specific stem cells (105). Organoid cultures have been established for different mouse and human tissues, including intestines, stomach, lungs, mammary gland, and prostate (108-114). A crucial requirement for establishing an organoid culture is the supplementation of organ-specific and well-defined stem cell niche factors in the culture medium. For example, to culture intestinal organoids, culture medium is supplemented with Wnt3a, EGF, Noggin, and R-spondin 1 (108). Organoids have been proven to be valuable models for studying different aspects developmental biology and stem cell research such as tissue morphogenesis, organogenesis, differentiation, heterotypic interactions between different cell types, and the effects of the ECM on cell differentiation and behavior. However, a current limitation of organoid cultures is the organoid dependence on a suitable three-dimensional matrix. Among the most commonly used scaffolds are collagen and Matrigel. These substrates, however, feature variable compositions and physical properties, which limits studies aiming to characterize the influence of the microenvironment on the organoid properties (105). Furthermore, these substrates pose risks of immunologic reactions and pathogen transfer and are, therefore, unsuitable for clinical applications. Engineered synthetic ECM has emerged as an attractive approach to circumvent these limitations (115).

Engineered ECM, constructed as an artificial substrate, acts to mimic the original three-dimensional microenvironment of a given organ or tissue. Increasingly, sophisticated scaffolds comprised of materials, such as synthetic hydrogels and nanofibers, are frequently employed as artificial ECM substitutes. In addition to biochemical interactions in cell-cell and cell-ECM signaling, mechanical stimuli such as substrate stiffness, and tension forces can also be modeled in engineered ECM (115). In a recent publication Gjorevski et al. studied the effects of stiffness on the dynamics of single cell-derived intestinal organoid formation (116). While intermediate to high stiffness and the presence of fibronectin sustained the expansion of intestinal LGR5-positive stem cells, differentiation and organoid formation required softer matrices and the presence of laminin.

We believe that, in the near future, organoid culture and tissue engineering techniques will increase our power to understand the molecular interactions that regulate the adrenal cortex stem cell niche. Protocols to establish normal adrenocortical and cancer organoid cultures in bioengineered matrices are currently under development in our laboratory.

\section{AUTHOR CONTRIBUTIONS}

All authors equally contributed to this manuscript.

\section{FUNDING}

AL is supported by CAPES, grant number BEX 8726/13-2.

2. Chan LF, Metherell LA, Clark AJ. Effects of melanocortins on adrenal gland physiology. Eur J Pharmacol (2011) 660(1):171-80. doi:10.1016/ j.ejphar.2010.11.041

3. Kramer RE, Gallant S, Brownie AC. Actions of angiotensin II on aldosterone biosynthesis in the rat adrenal cortex. Effects on cytochrome 
P-450 enzymes of the early and late pathway. J Biol Chem (1980) 255(8): 3442-7.

4. Fujita K, Aguilera G, Catt KJ. The role of cyclic AMP in aldosterone production by isolated zona glomerulosa cells. J Biol Chem (1979) 254(17):8567-74.

5. Vidal V, Sacco S, Rocha AS, da Silva F, Panzolini C, Dumontet T, et al. The adrenal capsule is a signaling center controlling cell renewal and zonation through Rspo3. Genes Dev (2016) 30(12):1389-94. doi:10.1101/ gad.277756.116

6. Guasti L, Cavlan D, Cogger K, Banu Z, Shakur A, Latif S, et al. Dlk1 up-regulates Gli1 expression in male rat adrenal capsule cells through the activation of betal integrin and ERK1/2. Endocrinology (2013) 154(12):4675-84. doi:10.1210/en.2013-1211

7. Revest JM, Spencer-Dene B, Kerr K, De Moerlooze L, Rosewell I, Dickson C, et al. Fibroblast growth factor receptor 2-IIIb acts upstream of Shh and Fgf4 and is required for limb bud maintenance but not for the induction of Fgf8, Fgf10, Msx1, or Bmp4. Dev Biol (2001) 231(1):47-62. doi:10.1006/ dbio.2000.0144

8. King P, Paul A, Laufer E. Shh signaling regulates adrenocortical development and identifies progenitors of steroidogenic lineages. Proc Natl Acad Sci U S A (2009) 106(50):21185-90. doi:10.1073/pnas.0909471106

9. Mesiano S, Jaffe RB. Developmental and functional biology of the primate fetal adrenal cortex. Endocr Rev (1997) 18(3):378-403. doi:10.1210/ edrv.18.3.0304

10. Morohashi K. The ontogenesis of the steroidogenic tissues. Genes Cells (1997) 2(2):95-106. doi:10.1046/j.1365-2443.1997.1060304.x

11. Ikeda Y, Shen WH, Ingraham HA, Parker KL. Developmental expression of mouse steroidogenic factor-1, an essential regulator of the steroid hydroxylases. Mol Endocrinol (1994) 8(5):654-62. doi:10.1210/mend.8.5.8058073

12. Val P, Martinez-Barbera JP, Swain A. Adrenal development is initiated by Cited 2 and Wt1 through modulation of Sf-1 dosage. Development (2007) 134(12):2349-58. doi:10.1242/dev.004390

13. Keegan CE, Hammer GD. Recent insights into organogenesis of the adrenal cortex. Trends Endocrinol Metab (2002) 13(5):200-8. doi:10.1016/ S1043-2760(02)00602-1

14. Zubair M, Parker KL, Morohashi K. Developmental links between the fetal and adult zones of the adrenal cortex revealed by lineage tracing. Mol Cell Biol (2008) 28(23):7030-40. doi:10.1128/MCB.00900-08

15. Narasaka T, Suzuki T, Moriya T, Sasano H. Temporal and spatial distribution of corticosteroidogenic enzymes immunoreactivity in developing human adrenal. Mol Cell Endocrinol (2001) 174(1-2):111-20. doi:10.1016/ S0303-7207(00)00445-7

16. Sucheston ME, Cannon MS. Development of zonular patterns in the human adrenal gland. J Morphol (1968) 126(4):477-91. doi:10.1002/ jmor.1051260408

17. Conley AJ, Bernstein RM, Nguyen AD. Adrenarche in nonhuman primates: the evidence for it and the need to redefine it. JEndocrinol (2012) 214(2):121-31. doi:10.1530/JOE-11-0467

18. Luo X, Ikeda Y, Parker KL. A cell-specific nuclear receptor is essential for adrenal and gonadal development and sexual differentiation. Cell (1994) 77(4):481-90. doi:10.1016/0092-8674(94)90211-9

19. Lala DS, Rice DA, Parker KL. Steroidogenic factor I, a key regulator of steroidogenic enzyme expression, is the mouse homolog of fushi tarazu-factor I. Mol Endocrinol (1992) 6(8):1249-58. doi:10.1210/mend.6.8.1406703

20. Honda S, Morohashi K, Nomura M, Takeya H, Kitajima M, Omura T. Ad4BP regulating steroidogenic $\mathrm{P}-450$ gene is a member of steroid hormone receptor superfamily. J Biol Chem (1993) 268(10):7494-502.

21. Bamforth SD, Bragança J, Eloranta JJ, Murdoch JN, Marques FI, Kranc KR, et al. Cardiac malformations, adrenal agenesis, neural crest defects and exencephaly in mice lacking Cited2, a new Tfap2 co-activator. Nat Genet (2001) 29(4):469-74. doi:10.1038/ng768

22. Moore AW, McInnes L, Kreidberg J, Hastie ND, Schedl A. YAC complementation shows a requirement for Wt1 in the development of epicardium, adrenal gland and throughout nephrogenesis. Development (1999) 126(9):1845-57.

23. Schnabel CA, Selleri L, Cleary ML. Pbx1 is essential for adrenal development and urogenital differentiation. Genesis (2003) 37(3):123-30. doi:10.1002/ gene. 10235

24. Wood MA, Acharya A, Finco I, Swonger JM, Elston MJ, Tallquist MD, et al. Fetal adrenal capsular cells serve as progenitor cells for steroidogenic and stromal adrenocortical cell lineages in M. musculus. Development (2013) 140(22):4522-32. doi:10.1242/dev.092775

25. Sewer MB, Nguyen VQ, Huang CJ, Tucker PW, Kagawa N, Waterman MR. Transcriptional activation of human CYP17 in H295R adrenocortical cells depends on complex formation among $\mathrm{p} 54(\mathrm{nrb}) / \mathrm{NonO}$, protein-associated splicing factor, and SF-1, a complex that also participates in repression of transcription. Endocrinology (2002) 143(4):1280-90. doi:10.1210/ endo.143.4.8748

26. Ito M, Yu R, Jameson JL. DAX-1 inhibits SF-1-mediated transactivation via a carboxy-terminal domain that is deleted in adrenal hypoplasia congenita. Mol Cell Biol (1997) 17(3):1476-83. doi:10.1128/MCB.17.3.1476

27. Babu PS, Bavers DL, Beuschlein F, Shah S, Jeffs B, Jameson JL, et al. Interaction between Dax-1 and steroidogenic factor-1 in vivo: increased adrenal responsiveness to ACTH in the absence of Dax-1. Endocrinology (2002) 143(2):665-73. doi:10.1210/endo.143.2.8658

28. Scheys JO, Heaton JH, Hammer GD. Evidence of adrenal failure in aging Dax1-deficient mice. Endocrinology (2011) 152(9):3430-9. doi:10.1210/ en.2010-0986

29. Ingle D, Higgins G. Autotransplantation and regeneration of the adrenal gland. Endocrinology (1938) 22:458-64. doi:10.1210/endo-22-4-458

30. Thomas M, Hornsby PJ. Transplantation of primary bovine adrenocortical cells into scid mice. Mol Cell Endocrinol (1999) 153(1-2):125-36. doi:10.1016/ S0303-7207(99)00070-2

31. Thomas M, Northrup SR, Hornsby PJ. Adrenocortical tissue formed by transplantation of normal clones of bovine adrenocortical cells in scid mice replaces the essential functions of the animals' adrenal glands. Nat Med (1997) 3(9):978-83. doi:10.1038/nm0997-978

32. Gottschau M. Struktur und embryonale Entwicklung der Nebennieren bei Säugetieren. Archiv Anatomie Physiologie (1883) 412-458:412-58.

33. Arnold J.Ein beitrag zu der feineren structur und demchemismus der nenemmieren. Virchows Arch (1866) 39:64-117. doi:10.1007/BF 01979887

34. Vinson GP. Functional zonation of the adult mammalian adrenal cortex. Front Neurosci (2016) 10:238. doi:10.3389/fnins.2016.00238

35. Chang SP, Morrison HD, Nilsson F, Kenyon CJ, West JD, Morley SD. Cell proliferation, movement and differentiation during maintenance of the adult mouse adrenal cortex. PLoS One (2013) 8(12):e81865. doi:10.1371/journal. pone. 0081865

36. Miyamoto H, Mitani F, Mukai K, Suematsu M, Ishimura Y. Studies on cytogenesis in adult rat adrenal cortex: circadian and zonal variations and their modulation by adrenocorticotropic hormone. J Biochem (1999) 126(6):1175-83. doi:10.1093/oxfordjournals.jbchem.a022564

37. Bertholet JY. Proliferative activity and cell migration in the adrenal cortex of fetal and neonatal rats: an autoradiographic study. J Endocrinol (1980) 87(1):1-9. doi:10.1677/joe.0.0870001

38. Iannaccone PM, Weinberg WC. The histogenesis of the rat adrenal cortex: a study based on histologic analysis of mosaic pattern in chimeras. J Exp Zool (1987) 243(2):217-23. doi:10.1002/jez.1402430207

39. Hu MC, Chou SJ, Huang YY, Hsu NC, Li H, Chung BC. Tissue-specific, hormonal, and developmental regulation of SCC-LacZ expression in transgenic mice leads to adrenocortical zone characterization. Endocrinology (1999) 140(12):5609-18. doi:10.1210/endo.140.12.7177

40. Morley SD, Viard I, Chung BC, Ikeda Y, Parker KL, Mullins JJ. Variegated expression of a mouse steroid 21-hydroxylase/beta-galactosidase transgene suggests centripetal migration of adrenocortical cells. Mol Endocrinol (1996) 10(5):585-98. doi:10.1210/mend.10.5.8732689

41. Freedman BD, Kempna PB, Carlone DL, Shah MS, Guagliardo NA, Barrett $\mathrm{PQ}$, et al. Adrenocortical zonation results from lineage conversion of differentiated zona glomerulosa cells. Dev Cell (2013) 26(6):666-73. doi:10.1016/j. devcel.2013.07.016

42. Nusse R. Wnt signaling. Cold Spring Harb Perspect Biol (2012) 4(5):a011163. doi:10.1101/cshperspect.a011163

43. Kim AC, Reuter AL, Zubair M, Else T, Serecky K, Bingham NC, et al. Targeted disruption of beta-catenin in Sf1-expressing cells impairs development and maintenance of the adrenal cortex. Development (2008) 135(15):2593-602. doi: $10.1242 /$ dev. 021493

44. Walczak EM, Kuick R, Finco I, Bohin N, Hrycaj SM, Wellik DM, et al. Wnt signaling inhibits adrenal steroidogenesis by cell-autonomous and 
non-cell-autonomous mechanisms. Mol Endocrinol (2014) 28(9):1471-86. doi:10.1210/me.2014-1060

45. Usongo M, Farookhi R. beta-catenin/Tcf-signaling appears to establish the murine ovarian surface epithelium (OSE) and remains active in selected postnatal OSE cells. BMC Dev Biol (2012) 12:17. doi:10.1186/1471-213X-12-17

46. Walczak EM, Hammer GD. Regulation of the adrenocortical stem cell niche: implications for disease. Nat Rev Endocrinol (2015) 11(1):14-28. doi:10.1038/ nrendo.2014.166

47. Finco I, LaPensee CR, Krill KT, Hammer GD. Hedgehog signaling and steroidogenesis. Annu Rev Physiol (2015) 77:105-29. doi:10.1146/ annurev-physiol-061214-111754

48. Guasti L, Paul A, Laufer E, King P. Localization of Sonic hedgehog secreting and receiving cells in the developing and adult rat adrenal cortex. Mol Cell Endocrinol (2011) 336(1-2):117-22. doi:10.1016/j.mce.2010.11.010

49. Laufer E, Kesper D, Vortkamp A, King P. Sonic hedgehog signaling during adrenal development. Mol Cell Endocrinol (2012) 351(1):19-27. doi:10.1016/j. mce.2011.10.002

50. Bandiera R, Vidal VP, Motamedi FJ, Clarkson M, Sahut-Barnola I, von Gise A, et al. WT1 maintains adrenal-gonadal primordium identity and marks a population of AGP-like progenitors within the adrenal gland. Dev Cell (2013) 27(1):5-18. doi:10.1016/j.devcel.2013.09.003

51. Morrison SJ, Spradling AC. Stem cells and niches: mechanisms that promote stem cell maintenance throughout life. Cell (2008) 132(4):598-611. doi:10.1016/j.cell.2008.01.038

52. Simon DP, Hammer GD. Adrenocortical stem and progenitor cells: implications for adrenocortical carcinoma. Mol Cell Endocrinol (2012) 351(1):2-11. doi:10.1016/j.mce.2011.12.006

53. Kim A, Giordano TJ, Kuick R, Serecky K, Hammer GD. Wnt/betacatenin signaling in adrenocortical stem/progenitor cells: implications for adrenocortical carcinoma. Ann Endocrinol (Paris) (2009) 70(3):156. doi:10.1016/j. ando.2009.02.006

54. Mandel H, Shemer R, Borochowitz ZU, Okopnik M, Knopf C, Indelman $\mathrm{M}$, et al. SERKAL syndrome: an autosomal-recessive disorder caused by a loss-of-function mutation in WNT4. Am J Hum Genet (2008) 82(1):39-47. doi:10.1016/j.ajhg.2007.08.005

55. Heikkilä M, Peltoketo H, Leppäluoto J, Ilves M, Vuolteenaho O, Vainio S. Wnt-4 deficiency alters mouse adrenal cortex function, reducing aldosterone production. Endocrinology (2002) 143(11):4358-65. doi:10.1210/ en.2002-220275

56. Jeays-Ward K, Hoyle C, Brennan J, Dandonneau M, Alldus G, Capel B, et al. Endothelial and steroidogenic cell migration are regulated by WNT4 in the developing mammalian gonad. Development (2003) 130(16):3663-70. doi:10.1242/dev.00591

57. Zheng S, Cherniack AD, Dewal N, Moffitt RA, Danilova L, Murray BA, et al. Comprehensive pan-genomic characterization of adrenocortical carcinoma. Cancer Cell (2016) 29(5):723-36. doi:10.1016/j.ccell.2016.04.002

58. Drelon C, Berthon A, Sahut-Barnola I, Mathieu M, Dumontet T, Rodriguez $\mathrm{S}$, et al. PKA inhibits WNT signalling in adrenal cortex zonation and prevents malignant tumour development. Nat Commun (2016) 7:12751. doi:10.1038/ ncomms 12751

59. Tanigawa S, Wang H, Yang Y, Sharma N, Tarasova N, Ajima R, et al. Wnt4 induces nephronic tubules in metanephric mesenchyme by a non-canonical mechanism. Dev Biol (2011) 352(1):58-69. doi:10.1016/j.ydbio.2011.01.012

60. Heinonen KM, Vanegas JR, Lew D, Krosl J, Perreault C. Wnt4 enhances murine hematopoietic progenitor cell expansion through a planar cell polarity-like pathway. PLoS One (2011) 6(4):e19279. doi:10.1371/journal. pone.0019279

61. Bakrania P, Efthymiou M, Klein JC, Salt A, Bunyan DJ, Wyatt A, et al. Mutations in BMP4 cause eye, brain, and digit developmental anomalies: overlap between the BMP4 and hedgehog signaling pathways. Am J Hum Genet (2008) 82(2):304-19. doi:10.1016/j.ajhg.2007.09.023

62. Rege J, Nishimoto HK, Nishimoto K, Rodgers RJ, Auchus RJ, Rainey WE. Bone morphogenetic protein-4 (BMP4): a paracrine regulator of human adrenal C19 steroid synthesis. Endocrinology (2015) 156(7):2530-40. doi:10.1210/en.2014-1942

63. Kim JS, Crooks H, Dracheva T, Nishanian TG, Singh B, Jen J, et al. Oncogenic beta-catenin is required for bone morphogenetic protein 4 expression in human cancer cells. Cancer Res (2002) 62(10):2744-8.
64. Heaton JH, Wood MA, Kim AC, Lima LO, Barlaskar FM, Almeida MQ, et al. Progression to adrenocortical tumorigenesis in mice and humans through insulin-like growth factor 2 and beta-catenin. Am J Pathol (2012) 181(3):1017-33. doi:10.1016/j.ajpath.2012.05.026

65. Song X, Sato Y, Felemban A, Ito A, Hossain M, Ochiai H, et al. Equarin is involved as an FGF signaling modulator in chick lens differentiation. Dev Biol (2012) 368(1):109-17. doi:10.1016/j.ydbio.2012.05.029

66. Huang CC, Miyagawa S, Matsumaru D, Parker KL, Yao HH. Progenitor cell expansion and organ size of mouse adrenal is regulated by sonic hedgehog. Endocrinology (2010) 151(3):1119-28. doi:10.1210/en.2009-0814

67. Ching S, Vilain E. Targeted disruption of Sonic Hedgehog in the mouse adrenal leads to adrenocortical hypoplasia. Genesis (2009) 47(9):628-37. doi:10.1002/dvg.20532

68. Ornitz DM, Itoh $\mathrm{N}$. The fibroblast growth factor signaling pathway. Wiley Interdiscip Rev Dev Biol (2015) 4(3):215-66. doi:10.1002/wdev.176

69. Rodems TS, Iida M, Brand TM, Pearson HE, Orbuch RA, Flanigan BG, et al. Adaptive responses to antibody based therapy. Semin Cell Dev Biol (2016) 50:153-63. doi:10.1016/j.semcdb.2016.01.001

70. Gospodarowicz D, Handley HH. Stimulation of division of Y1 adrenal cells by a growth factor isolated from bovine pituitary glands. Endocrinology (1975) 97(1):102-7. doi:10.1210/endo-97-1-102

71. Gospodarowicz D, Ill CR, Hornsby PJ, Gill GN. Control of bovine adrenal cortical cell proliferation by fibroblast growth factor. Lack of effect of epidermal growth factor. Endocrinology (1977) 100(4):1080-9. doi:10.1210/ endo-100-4-1080

72. Crickard K, Ill CR, Jaffe RB. Control of proliferation of human fetal adrenal cells in vitro. JClin Endocrinol Metab (1981) 53(4):790-6. doi:10.1210/ jcem-53-4-790

73. Lepique AP, Moraes MS, Rocha KM, Eichler CB, Hajj GN, Schwindt TT, et al. c-Myc protein is stabilized by fibroblast growth factor 2 and destabilized by ACTH to control cell cycle in mouse Y1 adrenocortical cells. J Mol Endocrinol (2004) 33(3):623-38. doi:10.1677/jme.1.01485

74. Chu Y, Ho WJ, Dunn JC. Basic fibroblast growth factor delivery enhances adrenal cortical cellular regeneration. Tissue Eng Part A (2009) 15(8):2093101. doi:10.1089/ten.tea.2008.0305

75. Guasti L, Candy Sze WC, McKay T, Grose R, King PJ. FGF signalling through Fgfr2 isoform IIIb regulates adrenal cortex development. Mol Cell Endocrinol (2013) 371(1-2):182-8. doi:10.1016/j.mce.2013.01.014

76. Ornitz DM, Xu J, Colvin JS, McEwen DG, MacArthur CA, Coulier F, et al. Receptor specificity of the fibroblast growth factor family. J Biol Chem (1996) 271(25):15292-7. doi:10.1074/jbc.271.25.15292

77. Kim Y, Bingham N, Sekido R, Parker KL, Lovell-Badge R, Capel B. Fibroblast growth factor receptor 2 regulates proliferation and Sertoli differentiation during male sex determination. Proc Natl Acad Sci U S A (2007) 104(42):16558-63. doi:10.1073/pnas.0702581104

78. Smas CM, Sul HS. Pref-1, a protein containing EGF-like repeats, inhibits adipocyte differentiation. Cell (1993) 73(4):725-34. doi:10.1016/0092-8674(93)90252-L

79. Laborda J, Sausville EA, Hoffman T, Notario V. dlk, a putative mammalian homeotic gene differentially expressed in small cell lung carcinoma and neuroendocrine tumor cell line. J Biol Chem (1993) 268(6):3817-20.

80. Wang Y, Hudak C, Sul HS. Role of preadipocyte factor 1 in adipocyte differentiation. Clin Lipidol (2010) 5(1):109-15. doi:10.2217/clp.09.80

81. Wang Y, Sul HS. Pref-1 regulates mesenchymal cell commitment and differentiation through Sox9. Cell Metab (2009) 9(3):287-302. doi:10.1016/j. cmet.2009.01.013

82. Floridon C, Jensen CH, Thorsen P, Nielsen O, Sunde L, Westergaard JG, et al. Does fetal antigen 1 (FA1) identify cells with regenerative, endocrine and neuroendocrine potentials? A study of FA1 in embryonic, fetal, and placental tissue and in maternal circulation. Differentiation (2000) 66(1):49-59. doi:10.1046/j.1432-0436.2000.066001049.x

83. Mortensen SB, Jensen CH, Schneider M, Thomassen M, Kruse TA, Laborda J, et al. Membrane-tethered delta-like 1 homolog (DLK1) restricts adipose tissue size by inhibiting preadipocyte proliferation. Diabetes (2012) 61(11):2814-22. doi:10.2337/db12-0176

84. Carithers LJ, Ardlie K, Barcus M, Branton PA, Britton A, Buia SA, et al. A novel approach to high-quality postmortem tissue procurement: the GTEx project. Biopreserv Biobank (2015) 13(5):311-9. doi:10.1089/bio.2015.0032 
85. Halder SK, Takemori H, Hatano O, Nonaka Y, Wada A, Okamoto M. Cloning of a membrane-spanning protein with epidermal growth factor-like repeat motifs from adrenal glomerulosa cells. Endocrinology (1998) 139(7):3316-28. doi:10.1210/endo.139.7.6081

86. Okamoto M, Takemori H, Halder SK, Nonaka Y, Hatano O. Implication of ZOG protein (zona glomerulosa-specific protein) in zone development of the adrenal cortex. Endocr Res (1998) 24(3-4):515-20. doi:10.3109/07435809809032640

87. Mitani F, Mukai K, Miyamoto H, Suematsu M, Ishimura Y. The undifferentiated cell zone is a stem cell zone in adult rat adrenal cortex. Biochim Biophys Acta (2003) 1619(3):317-24. doi:10.1016/S0304-4165(02)00490-7

88. Kim KA, Zhao J, Andarmani S, Kakitani M, Oshima T, Binnerts ME, et al. R-Spondin proteins: a novel link to beta-catenin activation. Cell Cycle (2006) 5(1):23-6. doi:10.4161/cc.5.1.2305

89. de Lau WB, Snel B, Clevers HC. The R-spondin protein family. Genome Biol (2012) 13(3):242. doi:10.1186/gb-2012-13-3-242

90. Rocha AS, Vidal V, Mertz M, Kendall TJ, Charlet A, Okamoto H, et al. The angiocrine factor rspondin 3 is a key determinant of liver zonation. Cell Rep (2015) 13(9):1757-64. doi:10.1016/j.celrep.2015.10.049

91. Barker N, Tan S, Clevers H. Lgr proteins in epithelial stem cell biology. Development (2013) 140(12):2484-94. doi:10.1242/dev.083113

92. Hao HX, Xie Y, Zhang Y, Charlat O, Oster E, Avello M, et al. ZNRF3 promotes Wnt receptor turnover in an R-spondin-sensitive manner. Nature (2012) 485(7397):195-200. doi:10.1038/nature11019

93. Hynes RO, Naba A. Overview of the matrisome - an inventory of extracellular matrix constituents and functions. Cold Spring Harb Perspect Biol (2012) 4(1):a004903. doi:10.1101/cshperspect.a004903

94. Hynes RO. The extracellular matrix: not just pretty fibrils. Science (2009) 326(5957):1216-9. doi:10.1126/science.1176009

95. Brizzi MF, Tarone G, Defilippi P. Extracellular matrix, integrins, and growth factors as tailors of the stem cell niche. Curr Opin Cell Biol (2012) 24(5):645-51. doi:10.1016/j.ceb.2012.07.001

96. Ellis SJ, Tanentzapf G. Integrin-mediated adhesion and stem-cell-niche interactions. Cell Tissue Res (2010) 339(1):121-30. doi:10.1007/s00441-009-0828-4

97. Taddei I, Deugnier MA, Faraldo MM, Petit V, Bouvard D, Medina D, et al. Betal integrin deletion from the basal compartment of the mammary epithelium affects stem cells. Nat Cell Biol (2008) 10(6):716-22. doi:10.1038/ ncb1734

98. Qiu Y, Bayomy AF, Gomez MV, Bauer M, Du P, Yang Y, et al. A role for matrix stiffness in the regulation of cardiac side population cell function. Am J Physiol Heart Circ Physiol (2015) 308(9):H990-7. doi:10.1152/ajpheart.00935.2014

99. Ahmed M, Ffrench-Constant C. Extracellular matrix regulation of stem cell behavior. Curr Stem Cell Rep (2016) 2:197-206. doi:10.1007/ s40778-016-0056-2

100. Campbell S, Otis M, Côté M, Gallo-Payet N, Payet MD. Connection between integrins and cell activation in rat adrenal glomerulosa cells: a role for Arg-Gly-Asp peptide in the activation of the p42/p44(mapk) pathway and intracellular calcium. Endocrinology (2003) 144(4):1486-95. doi:10.1210/ en.2002-220903

101. Chamoux E, Bolduc L, Lehoux JG, Gallo-Payet N. Identification of extracellular matrix components and their integrin receptors in the human fetal adrenal gland. J Clin Endocrinol Metab (2001) 86(5):2090-8. doi:10.1210/ jcem.86.5.7462

102. Chamoux E, Narcy A, Lehoux JG, Gallo-Payet N. Fibronectin, laminin, and collagen IV interact with ACTH and angiotensin II to dictate specific cell behavior and secretion in human fetal adrenal cells in culture. Endocr Res (2002) 28(4):637-40. doi:10.1081/ERC-120016978
103. Otis M, Campbell S, Payet MD, Gallo-Payet N. Expression of extracellular matrix proteins and integrins in rat adrenal gland: importance for ACTHassociated functions. JEndocrinol (2007) 193(3):331-47. doi:10.1677/ JOE-07-0055

104. Shamir ER, Ewald AJ. Three-dimensional organotypic culture: experimental models of mammalian biology and disease. Nat Rev Mol Cell Biol (2014) 15(10):647-64. doi:10.1038/nrm3873

105. Kretzschmar K, Clevers H. Organoids: modeling development and the stem cell niche in a dish. Dev Cell (2016) 38(6):590-600. doi:10.1016/j. devcel.2016.08.014

106. Eiraku M, Sasai Y. Self-formation of layered neural structures in three-dimensional culture of ES cells. Curr Opin Neurobiol (2012) 22(5):768-77. doi:10.1016/j.conb.2012.02.005

107. Lancaster MA, Knoblich JA. Organogenesis in a dish: modeling development and disease using organoid technologies. Science (2014) 345(6194):1247125. doi:10.1126/science. 1247125

108. Sato T, Vries RG, Snippert HJ, van de Wetering M, Barker N, Stange DE, et al. Single Lgr5 stem cells build crypt-villus structures in vitro without a mesenchymal niche. Nature (2009) 459(7244):262-5. doi:10.1038/nature07935

109. Sato T, Stange DE, Ferrante M, Vries RG, Van Es JH, Van den Brink S, et al. Long-term expansion of epithelial organoids from human colon, adenoma, adenocarcinoma, and Barrett's epithelium. Gastroenterology (2011) 141(5):1762-72. doi:10.1053/j.gastro.2011.07.050

110. Karthaus WR, Iaquinta PJ, Drost J, Gracanin A, van Boxtel R, Wongvipat J, et al. Identification of multipotent luminal progenitor cells in human prostate organoid cultures. Cell (2014) 159(1):163-75. doi:10.1016/j.cell.2014.08.017

111. Linnemann JR, Miura H, Meixner LK, Irmler M, Kloos UJ, Hirschi B, et al. Quantification of regenerative potential in primary human mammary epithelial cells. Development (2015) 142(18):3239-51. doi:10.1242/dev.123554

112. Barker N, Huch M, Kujala P, van de Wetering M, Snippert HJ, van Es JH, et al. Lgr5(+ve) stem cells drive self-renewal in the stomach and build longlived gastric units in vitro. Cell Stem Cell (2010) 6(1):25-36. doi:10.1016/j. stem.2009.11.013

113. Bartfeld S, Bayram T, van de Wetering M, Huch M, Begthel H, Kujala P, et al. In vitro expansion of human gastric epithelial stem cells and their responses to bacterial infection. Gastroenterology (2015) 148(1):126-136e6. doi:10.1053/j.gastro.2014.09.042

114. Desai TJ, Brownfield DG, Krasnow MA. Alveolar progenitor and stem cells in lung development, renewal and cancer. Nature (2014) 507(7491):190-4. doi:10.1038/nature 12930

115. Magin CM, Alge DL, Anseth KS. Bio-inspired 3D microenvironments: a new dimension in tissue engineering. Biomed Mater (2016) 11(2):022001. doi:10.1088/1748-6041/11/2/022001

116. Gjorevski N, Sachs N, Manfrin A, Giger S, Bragina ME, Ordóñez-Morán P, et al. Designer matrices for intestinal stem cell and organoid culture. Nature (2016) 539(7630):560-4. doi:10.1038/nature20168

Conflict of Interest Statement: The authors declare that the research was conducted in the absence of any commercial or financial relationships that could be construed as a potential conflict of interest.

Copyright (c) 2017 Lerario, Finco, LaPensee and Hammer. This is an open-access article distributed under the terms of the Creative Commons Attribution License (CC BY). The use, distribution or reproduction in other forums is permitted, provided the original author(s) or licensor are credited and that the original publication in this journal is cited, in accordance with accepted academic practice. No use, distribution or reproduction is permitted which does not comply with these terms. 